ARTICLE

https://doi.org/10.1038/s41467-018-08120-x

\title{
Over 56.55\% Faradaic efficiency of ambient ammonia synthesis enabled by positively shifting the reaction potential
}

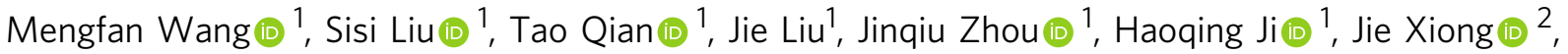 \\ Jun Zhong ${ }^{3} \&$ Chenglin Yan ${ }^{1}{ }^{1}$
}

Ambient electrochemical $N_{2}$ reduction is emerging as a highly promising alternative to the Haber-Bosch process but is typically hampered by a high reaction barrier and competing hydrogen evolution, leading to an extremely low Faradaic efficiency. Here, we demonstrate that under ambient conditions, a single-atom catalyst, iron on nitrogen-doped carbon, could positively shift the ammonia synthesis process to an onset potential of $0.193 \mathrm{~V}$, enabling a dramatically enhanced Faradaic efficiency of 56.55\%. The only doublet coupling representing ${ }^{15} \mathrm{NH}_{4}{ }^{+}$in an isotopic labeling experiment confirms reliable $\mathrm{NH}_{3}$ production data. Molecular dynamics simulations suggest efficient $\mathrm{N}_{2}$ access to the single-atom iron with only a small energy barrier, which benefits preferential $\mathrm{N}_{2}$ adsorption instead of $\mathrm{H}$ adsorption via a strong exothermic process, as further confirmed by first-principle calculations. The released energy helps promote the following process and the reaction bottleneck, which is widely considered to be the first hydrogenation step, is successfully overcome.

\footnotetext{
${ }^{1}$ College of Energy, Key Laboratory of Advanced Carbon Materials and Wearable Energy Technologies of Jiangsu Province, Soochow University, 215006 Suzhou, China. ${ }^{2}$ University of Electronic Science and Technology of China, 610054 Chengdu Sichuan, China. ${ }^{3}$ Institute of Functional Nano and Soft Materials (FUNSOM), Jiangsu Key Laboratory for Carbon-Based Functional Materials and Devices, Soochow University, 215123 Suzhou, China. These authors contributed equally: Mengfan Wang, Sisi Liu. Correspondence and requests for materials should be addressed to T.Q. (email: taian@suda.edu.cn) or to C.Y. (email: c.yan@suda.edu.cn)
} 
K nown as the most common industrial chemical, ammonia $\left(\mathrm{NH}_{3}\right)$ is provoking much attention as a highly efficient energy carrier with low liquefying pressure and high hydrogen density ${ }^{1}$. Its synthesis from the hydrogenation of atmospheric nitrogen $\left(\mathrm{N}_{2}\right)$, however, is extremely difficult due to the inherent nature of the $\mathrm{N}-\mathrm{N}$ triple bond ${ }^{2}$. Industrially, $\mathrm{NH}_{3}$ manufacture is still dominated by the long-standing Haber-Bosch process under harsh conditions, which consumes more than $1 \%$ of the energy supply on earth ${ }^{3}$. However, this energy-intensive process can only achieve a relatively low conversion ratio due to the unfavorable chemical equilibrium ${ }^{4}$. Therefore, to alleviate these conditions, it is of great significance to develop alternative routes for more efficient $\mathrm{N}_{2}$ fixation under milder conditions. In response, a worldwide gold rush has been triggered, and many pioneering methods have been reported, including biological catalysis $^{5,6}$, photocatalysis ${ }^{7,8}$, and electrocatalysis ${ }^{9,10}$.

The electrochemical $\mathrm{N}_{2}$ reduction reaction (NRR) is emerging as a highly promising choice since it can be performed at atmospheric pressure and moderate temperature using a renewable electricity source ${ }^{11,12}$. From the thermodynamic view, the electrochemical NRR usually proceeds at similar potential to that required by the hydrogen evolution reaction (HER) ${ }^{13}$. In this case, the selectivity challenge comes from the competition between the binding of $\mathrm{N}_{2} \quad\left(\mathrm{~N}_{2}+{ }^{*} \rightarrow{ }^{\star} \mathrm{N}_{2}\right)$ and $\mathrm{H}\left(\mathrm{H}^{+}+e^{-}+{ }^{\star} \rightarrow{ }^{\star} \mathrm{H}\right)$, where ${ }^{\star}$ indicates the active site of the catalyst. Unfortunately, at relatively large applied potentials, most electrons and protons contribute to evolving hydrogen, accounting for the very low selectivity towards artificial synthesis of $\mathrm{NH}_{3}$ (ref. ${ }^{14}$ ). To increase the $\mathrm{NH}_{3}$ selectivity, it would be desirable to fabricate an electrocatalytic system that could lower the free energy barrier of ${ }^{\star} \mathrm{N}_{2}$ to compete with $\mathrm{H}$ for active sites and thus promote the NRR at low overpotentials. Once adsorbed $\mathrm{N}_{2}$ preoccupies the active sites instead of the undesirable coverage of hydrogen, the protons and electrons tend to attack the bound $\mathrm{N}_{2}$, leading to its hydrogenation and, finally, the synthesis of ammonia $^{13}$. To date, although some catalysts have been synthesized to improve nitrogen adsorption and alleviate reaction barriers $^{15-17}$, they still cannot efficiently separate the NRR from the HER and once the two reactions blur into each other, the Faradaic efficiency remains at very low levels. Accordingly, further efforts are needed to widen the potential gap between the NRR and the HER and to boost the NRR kinetics at low overpotentials to obtain reasonable performances.

Herein, we propose and demonstrate that a highly efficient and selective electrochemical NRR is indeed possible under ambient conditions by positively shifting the reaction potential. Starting with an onset potential of $0.193 \mathrm{~V}$ vs. reversible hydrogen electrode (RHE), the single-atom catalyst endowed the NRR with a superior Faradaic efficiency $(56.55 \%)$ and a desirable yield rate $\left(7.48 \mu \mathrm{gh}^{-1} \mathrm{mg}^{-1}\right)$ at $0 \mathrm{~V}$ vs. RHE. An isotopic labeling experiment using ${ }^{15} \mathrm{~N}_{2}$ as the feeding gas was carried out and only a doublet coupling representing ${ }^{15} \mathrm{NH}_{4}{ }^{+}$was observed in the spectra, confirming that the produced $\mathrm{NH}_{3}$ entirely comes from the electroreduction of $\mathrm{N}_{2}$. Such excellent performance is a joint effect of a suppressed HER and an enhanced NRR. Molecular dynamics (MD) simulations suggest only a small energy barrier of $2.38 \mathrm{~kJ} \mathrm{~mol}^{-1}$ for the access of the $\mathrm{N}_{2}$ molecule to the single-atom $\mathrm{Fe}$, benefiting efficient $\mathrm{N}_{2}$ delivery. The following adsorption is a strong exothermic reaction, as confirmed by density functional theory (DFT) calculations, and the energy released in this process could contribute to lowering the free energy barrier of the following hydrogenation, thus overcoming the reaction bottleneck of the whole process. On the other hand, considerably high energy barriers for ${ }^{\star} \mathrm{H}$ adsorption as well as its conversion into $\mathrm{H}_{2}$ are observed in the catalytic system, indicating inferior HER activity.

\section{Results}

Synthesis and characterization of the $\mathrm{Fe}_{\mathrm{SA}}-\mathrm{N}-\mathrm{C}$ catalyst. The proof-of-concept single-atom dispersed $\mathrm{Fe}-\mathrm{N}-\mathrm{C}\left(\mathrm{Fe}_{\mathrm{SA}}-\mathrm{N}-\mathrm{C}\right)$ catalyst was prepared by optimized modulation of the polypyrrole-iron coordination complex. Supplementary Fig. 1 and Fig. 1a indicate a graphene-like morphology of $\mathrm{Fe}_{\mathrm{SA}}-\mathrm{N}-\mathrm{C}$, with no observable nanoparticle phase of iron. Aberrationcorrected high-angle annular dark-field scanning transmission electron microscopy (HAADF-STEM) with subangstrom resolution was then conducted to elucidate the existing forms of Fe atoms. A large number of bright dots could be discerned in Fig. 1b, suggesting isolated iron atoms. The representative mapping images of the $\mathrm{Fe}_{\mathrm{SA}}-\mathrm{N}-\mathrm{C}$ sample in Fig. 1c further verify the uniform distribution of $\mathrm{Fe}$ atoms over the entire architecture along with $\mathrm{N}$, which acted as anchor points for the $\mathrm{Fe}^{18}$. The $\mathrm{Fe}$ content is approximately $1.09 \mathrm{wt} \%$, determined by inductively coupled plasma optical emission spectrometry analysis.

To further investigate the state of the Fe species at the atomic level, X-ray absorption near-edge structure (XANES) and extended X-ray absorption fine structure (EXAFS) analyses were carried out, with Fe foil as reference. In Fig. 1d, the absorption edge of $\mathrm{Fe}_{\mathrm{SA}}-\mathrm{N}-\mathrm{C}$ situates at more positive energy than does that of the Fe foil, implying that the isolated Fe single atoms bear positive charges. The Fourier transformed EXAFS curve of $\mathrm{Fe}_{\mathrm{SA}}-\mathrm{N}-\mathrm{C}$ only shows one distinct peak at approximately $1.44 \AA$, corresponding to the $\mathrm{Fe}-\mathrm{N}$ scattering paths. Moreover, no obvious Fe-Fe peak (2.2 $\AA$ ) or other peaks are observed (Fig. 1e). Iron atoms in $\mathrm{Fe}_{\mathrm{SA}}-\mathrm{N}-\mathrm{C}$ are thus confirmed to be stabilized by $\mathrm{N}$ atoms and atomically dispersed on the supports ${ }^{19}$. To probe the specific role of single Fe atoms, metal-free nitrogen-doped carbon (N-C) was synthesized for comparison (Supplementary Fig. 2). $\mathrm{X}$-ray diffraction (XRD) patterns show no distinct differences between $\mathrm{Fe}_{\mathrm{SA}}-\mathrm{N}-\mathrm{C}$ and $\mathrm{N}-\mathrm{C}$, with two broad peaks assignable to the (002) and (101) planes of graphitic carbon (Supplementary Fig. 3a), which can also be verified by the $I_{\mathrm{D}} / I_{\mathrm{G}}$ value in Raman spectra (Supplementary Fig. 3b). Notably, no peaks related to metallic Fe or other Fe species are observed in the XRD pattern of $\mathrm{Fe}_{\mathrm{SA}}-\mathrm{N}-\mathrm{C}$, further indicating the single-atomic nature of Fe.

Electroreduction of $\mathrm{N}_{2}$ to $\mathrm{NH}_{3}$ on the $\mathrm{Fe}_{\mathrm{SA}}-\mathrm{N}-\mathrm{C}$ catalyst. The electrochemical measurements were conducted under ambient conditions using a gas-tight electrocatalytic system, wherein the Nafion membrane separated the two parts of the cell (Supplementary Fig. 4). To evaluate the electrocatalytic performance of the catalysts for the NRR, linear sweep voltammograms were first measured in an Ar- or $\mathrm{N}_{2}$-saturated solution. For this, $0.1 \mathrm{M}$ $\mathrm{KOH}$ was chosen as the electrolyte. The HER in alkaline solution requires extra energy to break the water molecule, namely the strong covalent $\mathrm{H}-\mathrm{O}-\mathrm{H}$ bond, prior to hydrogen adsorption. Such an additional water dissociation step would make the entire process difficult to achieve at low overpotentials ${ }^{20}$. In an $\mathrm{N}_{2}$ environment, the current density of $\mathrm{N}-\mathrm{C}$ increases obviously when the potential is more negative than $-0.018 \mathrm{~V}$ vs. RHE, indicating the initiated NRR. For $\mathrm{Fe}_{\mathrm{SA}}-\mathrm{N}-\mathrm{C}$, its onset potential shifted markedly to a more positive potential of $0.193 \mathrm{~V}$ vs. RHE, suggesting that $\mathrm{Fe}_{\mathrm{SA}}-\mathrm{N}-\mathrm{C}$ is much more active than is $\mathrm{N}-\mathrm{C}$ for the NRR.

The NRR activity of $\mathrm{Fe}_{\mathrm{SA}}-\mathrm{N}-\mathrm{C}$ was then systematically studied in $0.1 \mathrm{M} \mathrm{KOH}$ with continuous $\mathrm{N}_{2}$ bubbling at various potentials (Supplementary Fig. 5). The indophenol blue method was used to detect the produced ammonia. To avoid production loss by $\mathrm{N}_{2}$ blowing during the test, another glass tube filled with $0.001 \mathrm{M}$ $\mathrm{H}_{2} \mathrm{SO}_{4}$ as the gas absorption liquid was set at the end of the cell. The total $\mathrm{NH}_{3}$ production yield was the summation of $\mathrm{NH}_{3}$ in the $0.1 \mathrm{M} \mathrm{KOH}$ and $0.001 \mathrm{M} \mathrm{H}_{2} \mathrm{SO}_{4}$ (Supplementary Figs. 6 and 7). 

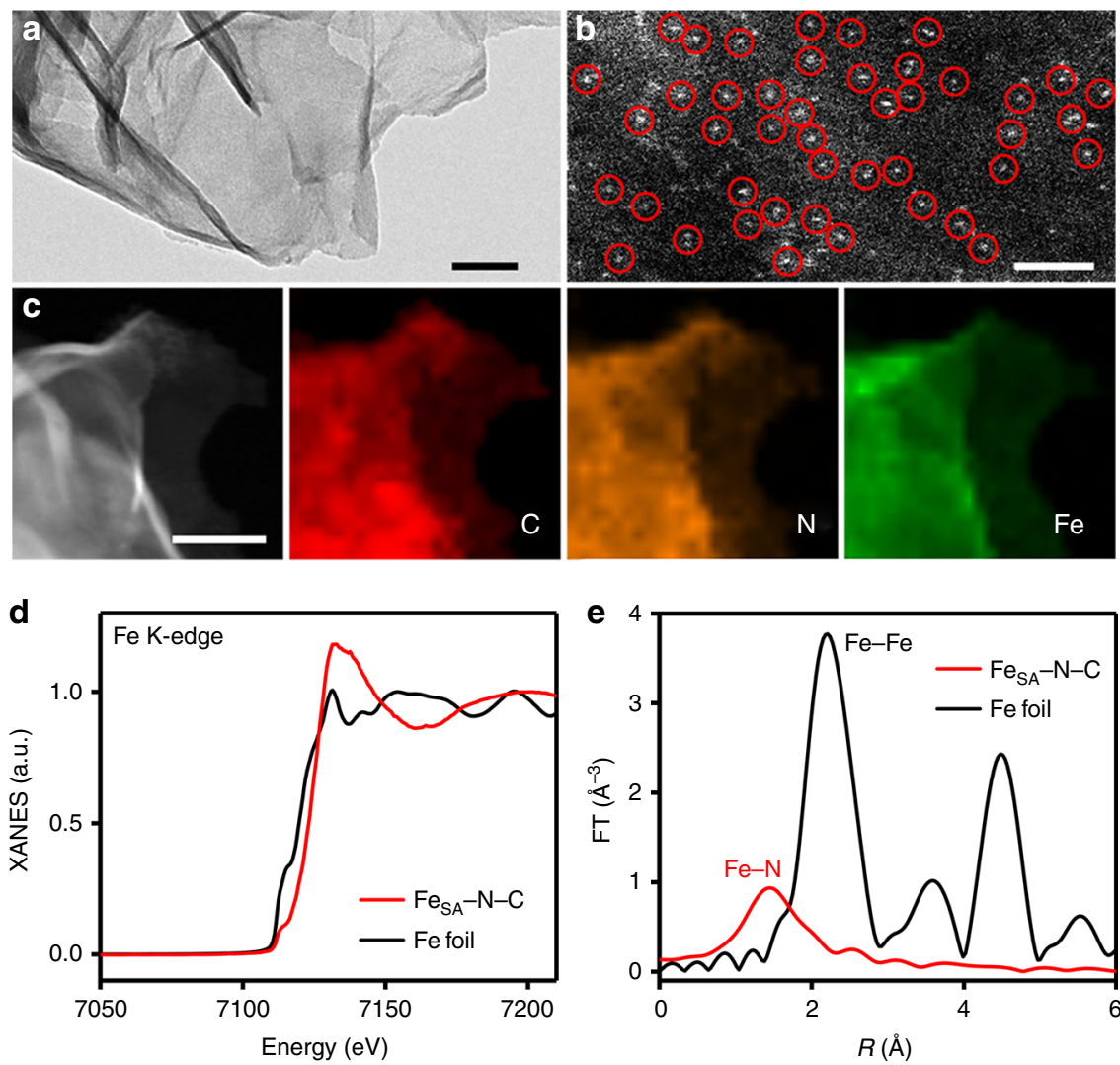

Fig. 1 Physical characterization. a Transmission electron microscopy (TEM) image of single-atom dispersed Fe-N-C (FesA-N-C). Scale bar, 50 nm. b Highangle annular dark-field scanning transmission electron microscopy (HAADF-STEM) image of $\mathrm{Fe}_{\mathrm{SA}}-\mathrm{N}-\mathrm{C}$. Single Fe atoms are highlighted by red circles. Scale bar, $2 \mathrm{~nm}$. c High-resolution TEM (HRTEM) image and corresponding element maps showing the distribution of C (red), N (orange), and Fe (green). Scale bar, $50 \mathrm{~nm}$. d X-ray absorption near-edge structure (XANES) spectra and e Fourier transform spectra at the Fe $\mathrm{K}$-edge of FesA-N-C and Fe foil

Hydrazine was another possible product and was detected by the Watt and Chrisp method (Supplementary Figs. 8 and 9), but no hydrazine was produced in our work. The average ammonia yields and corresponding Faradaic efficiencies of $\mathrm{Fe}_{\mathrm{SA}}-\mathrm{N}-\mathrm{C}$ are plotted in Fig. 2b. Strikingly, the highest Faradaic efficiency of $56.55 \%$ with a yield rate of $7.48 \mu \mathrm{g} \mathrm{h}^{-1} \mathrm{mg}^{-1}$ was achieved at $0 \mathrm{~V}$ vs. RHE. With negatively moving the applied potential, the adsorption of hydrogen species gradually outcompeted nitrogen on the electrode surface, leading to the HER as the primary reaction in the catalytic system. As a result, the Faradaic efficiency and the yield rate were cast into shade. To the best of our knowledge, such selectivity at $0 \mathrm{~V}$ vs. RHE is the highest among previously reported works under similar conditions (Supplementary Table 1).

To attest the superiority of $\mathrm{Fe}_{\mathrm{SA}}-\mathrm{N}-\mathrm{C}$, the potentiostatic NRR tests for $\mathrm{N}-\mathrm{C}$ were also conducted at the same potentials (Supplementary Fig. 10). As shown in Fig. 2c, for $\mathrm{N}-\mathrm{C}$, the highest NRR Faradaic efficiency is only $9.34 \%$, which is a sixth of that of $\mathrm{Fe}_{\mathrm{SA}}-\mathrm{N}-\mathrm{C}$. The double-layer capacitance $\left(C_{\mathrm{dl}}\right)$ was calculated to determine the electrochemical active surface area (ECSA) of each sample (Supplementary Fig. 11). The surfacearea-normalized yield rate of $\mathrm{NH}_{3}$ on $\mathrm{Fe}_{\mathrm{SA}}-\mathrm{N}-\mathrm{C}$ shows a greater advantage over the mass-normalized activity, corresponding to a 2.6-fold improvement compared with $\mathrm{N}-\mathrm{C}$ towards the NRR (Fig. 2d). The hydrogen evolution selectivity was tested to support this huge performance gap (Fig. 2e). For $\mathrm{Fe}_{\mathrm{SA}}-\mathrm{N}-\mathrm{C}$, with singleatom dispersed iron serving as active sites with a high selectivity of $\mathrm{N}_{2}$ adsorption with respect to $\mathrm{H}$ adsorption, inferior hydrogen evolution is observed at 0 vs. RHE. For $\mathrm{N}-\mathrm{C}$, its activity towards nitrogen reduction is relatively weak based on the narrow gap in the LSV curves of $\mathrm{N}_{2}$ and Ar-saturated environments, and most protons and electrons tend to evolve hydrogen. The surface-areanormalized activity of the HER was further calculated and compared in Fig. 2f. An $\mathrm{H}_{2}$ yield rate of $0.0029 \mu \mathrm{g} \mathrm{h}^{-1} \mathrm{~cm}_{\mathrm{ECSA}}{ }^{-2}$ was obtained on $\mathrm{Fe}_{\mathrm{SA}}-\mathrm{N}-\mathrm{C}$ at 0 vs. RHE, which is less than a fourth of that on $\mathrm{N}-\mathrm{C}\left(0.0125 \mu \mathrm{g} \mathrm{h}^{-1} \mathrm{~cm}_{\mathrm{ECSA}}{ }^{-2}\right)$, indicating that single $\mathrm{Fe}$ atoms could indeed retard the HER process. Based on the above results, we can conclude that the superior NRR activity of $\mathrm{Fe}_{\mathrm{SA}}-\mathrm{N}-\mathrm{C}$ derives from a joint effect of enhanced nitrogen reduction and suppressed hydrogen evolution.

As a further proof that the produced $\mathrm{NH}_{3}$ originated from the feeding $\mathrm{N}_{2},{ }^{15} \mathrm{~N}\left(99\right.$ atom\% $\left.{ }^{15} \mathrm{~N}\right)$ isotope labeling experiments were conducted ${ }^{21}$. Obviously, when ${ }^{15} \mathrm{~N}_{2}$ was supplied, no labeled ammonia was produced in the absence of an applied potential (Supplementary Fig. 12). After electrolysis at 0 vs. RHE, only doublet peaks representing ${ }^{15} \mathrm{NH}_{4}{ }^{+}$were observed in the ${ }^{1} \mathrm{H}$ nuclear magnetic resonance $\left({ }^{1} \mathrm{H}\right.$ NMR) spectra of the electrolyte, while no triple coupling indicating ${ }^{14} \mathrm{NH}_{4}{ }^{+}$could be detected (Fig. 3a). Moreover, the measured Faradaic efficiency and yield rate match well with that determined using ${ }^{14} \mathrm{~N}_{2}$ as the feeding gas (Fig. 3b), confirming that the produced $\mathrm{NH}_{3}$ in our study entirely comes from the electroreduction of $\mathrm{N}_{2}$ catalyzed by $\mathrm{Fe}_{\mathrm{SA}}-\mathrm{N}-\mathrm{C}$. In addition, control experiments without the $\mathrm{Fe}_{\mathrm{SA}}-\mathrm{N}-\mathrm{C}$ catalyst and with an Ar-saturated electrolyte were also performed as an alternative analytical method. As shown in Supplementary Fig. 13, the corresponding ultraviolet-visible (UV-vis) absorption spectra obtained using the indophenol blue method exhibit no apparent $\mathrm{NH}_{3}$ when using bare carbon paper as the working electrode. Similarly, upon conducting electrolysis on $\mathrm{Fe}_{\mathrm{SA}}-\mathrm{N}-\mathrm{C}$-coated carbon paper in an Ar-saturated solution, 
a
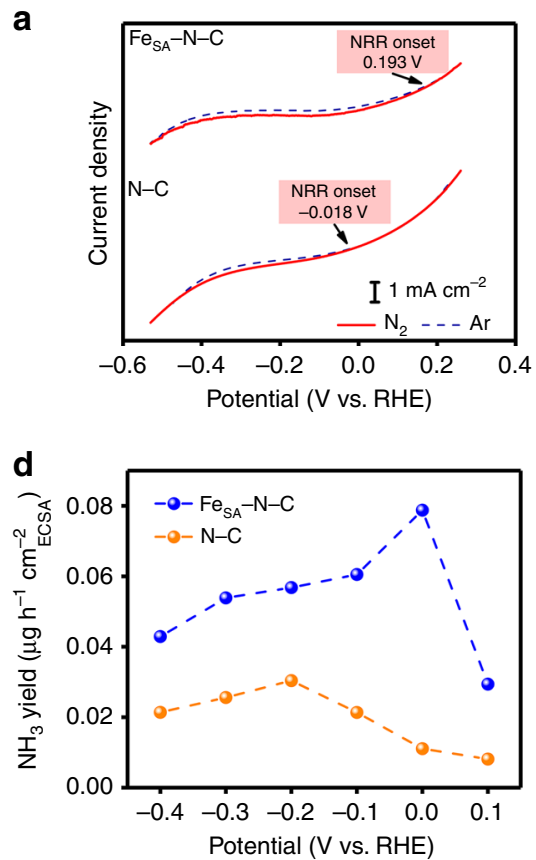

b
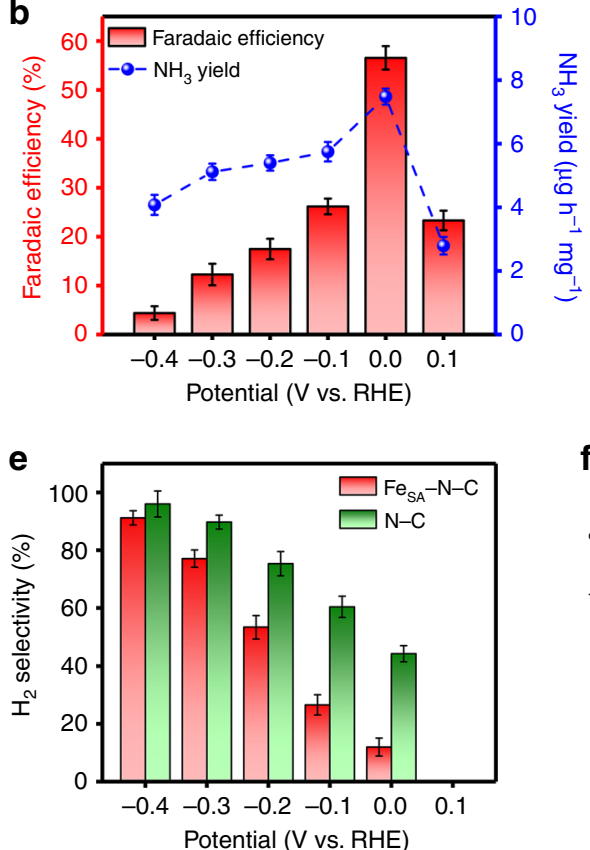

C
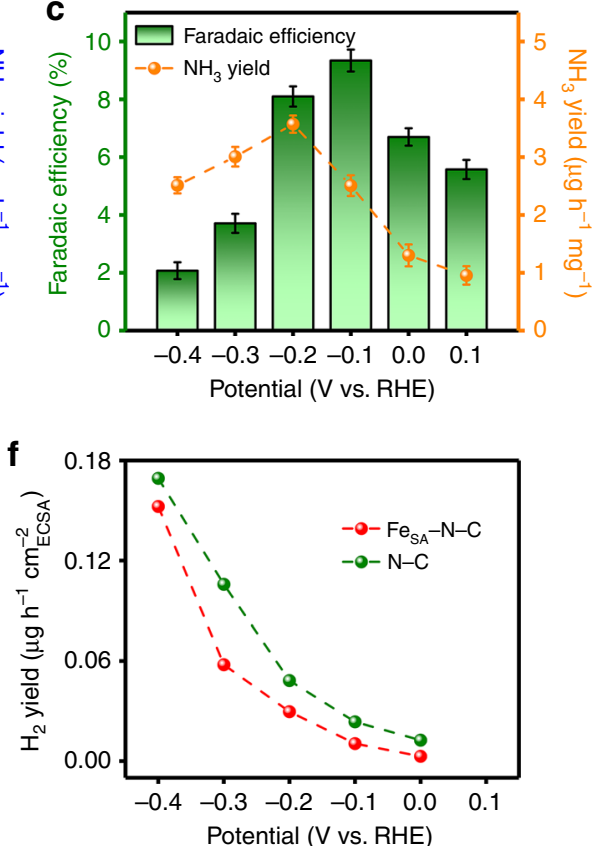

Fig. 2 Electroreduction of $\mathrm{N}_{2}$ to $\mathrm{NH}_{3}$ at ambient conditions. a Linear sweep voltammograms of single-atom dispersed Fe- $\mathrm{N}-\mathrm{C}$ (FesA-N-C) and nitrogendoped carbon $\left(\mathrm{N}-\mathrm{C}\right.$ ) in Ar-saturated (dashed line) or $\mathrm{N}_{2}$-saturated (solid line) $0.1 \mathrm{M} \mathrm{KOH}$ solution with a scan rate of $50 \mathrm{mV} \mathrm{s}^{-1}$. b NH $\mathrm{Naradaic}$ efficiencies and mass-normalized yield rates at each given potential of $\mathrm{Fe}_{\mathrm{SA}}-\mathrm{N}-\mathrm{C}$. $\mathbf{c} \mathrm{NH}_{3}$ Faradaic efficiencies and mass-normalized yield rates at each given potential of N-C. d Surface-area-normalized yield rate of $\mathrm{NH}_{3}$ production at different applied potentials on $\mathrm{Fe}_{S A}-\mathrm{N}-\mathrm{C}$ and $\mathrm{N}-\mathrm{C}$. e $\mathrm{H}_{2}$ selectivity of Fe $\mathrm{SA}_{\mathrm{A}}-\mathrm{N}-\mathrm{C}$ and $\mathrm{N}-\mathrm{C}$ at different potentials. The error bars correspond to the standard deviations of measurements over three separately prepared samples under the same conditions. $f$ Surface-area-normalized yield rate of $\mathrm{H}_{2}$ production at different applied potentials on $\mathrm{Fe}_{\mathrm{SA}}-\mathrm{N}-\mathrm{C}$ and $\mathrm{N}-\mathrm{C}$

a
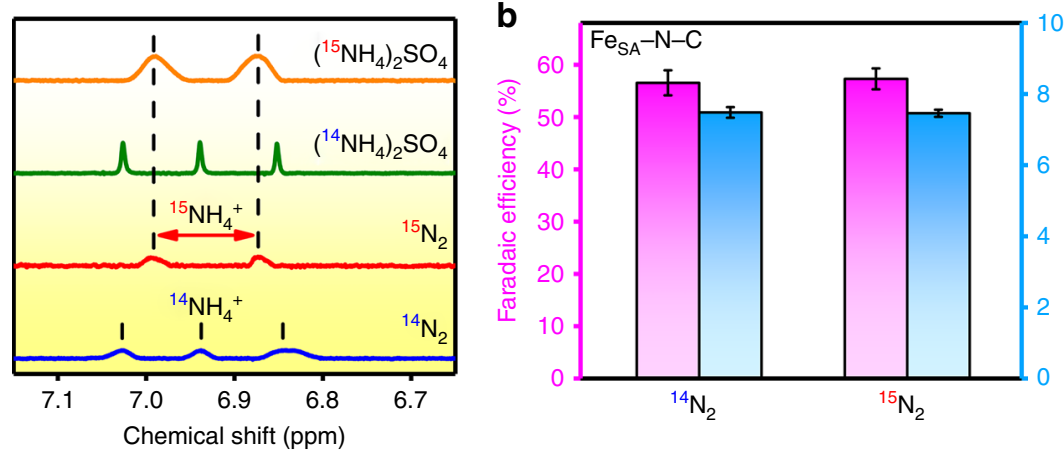

C

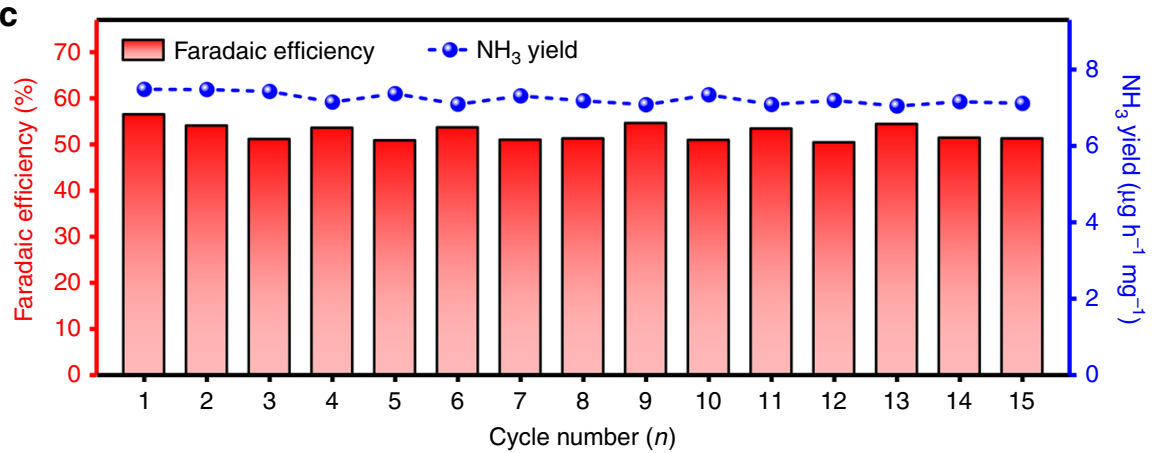

Fig. $3^{15} \mathrm{~N}$ isotope labeling experiment and stability test. $\mathbf{a}{ }^{15} \mathrm{~N}$ isotope labeling experiment. $\mathbf{b}$ Comparison of the Faradaic efficiency and ammonia yield rate using different feeding gases for the NRR at $\mathrm{V}$ V vs. reversible hydrogen electrode (RHE). The error bars correspond to the standard deviations of measurements over three separately prepared samples under the same conditions. c Faradaic efficiencies and $\mathrm{NH}_{3}$ yield rates of the single-atom dispersed $\mathrm{Fe}-\mathrm{N}-\mathrm{C}\left(\mathrm{Fe}_{\mathrm{SA}}-\mathrm{N}-\mathrm{C}\right)$ calculated after consecutive recycling electrolysis in $\mathrm{N}_{2}$-saturated $0.1 \mathrm{M} \mathrm{KOH}$ at $\mathrm{OV}$ vs. RHE for $1 \mathrm{~h}$ 

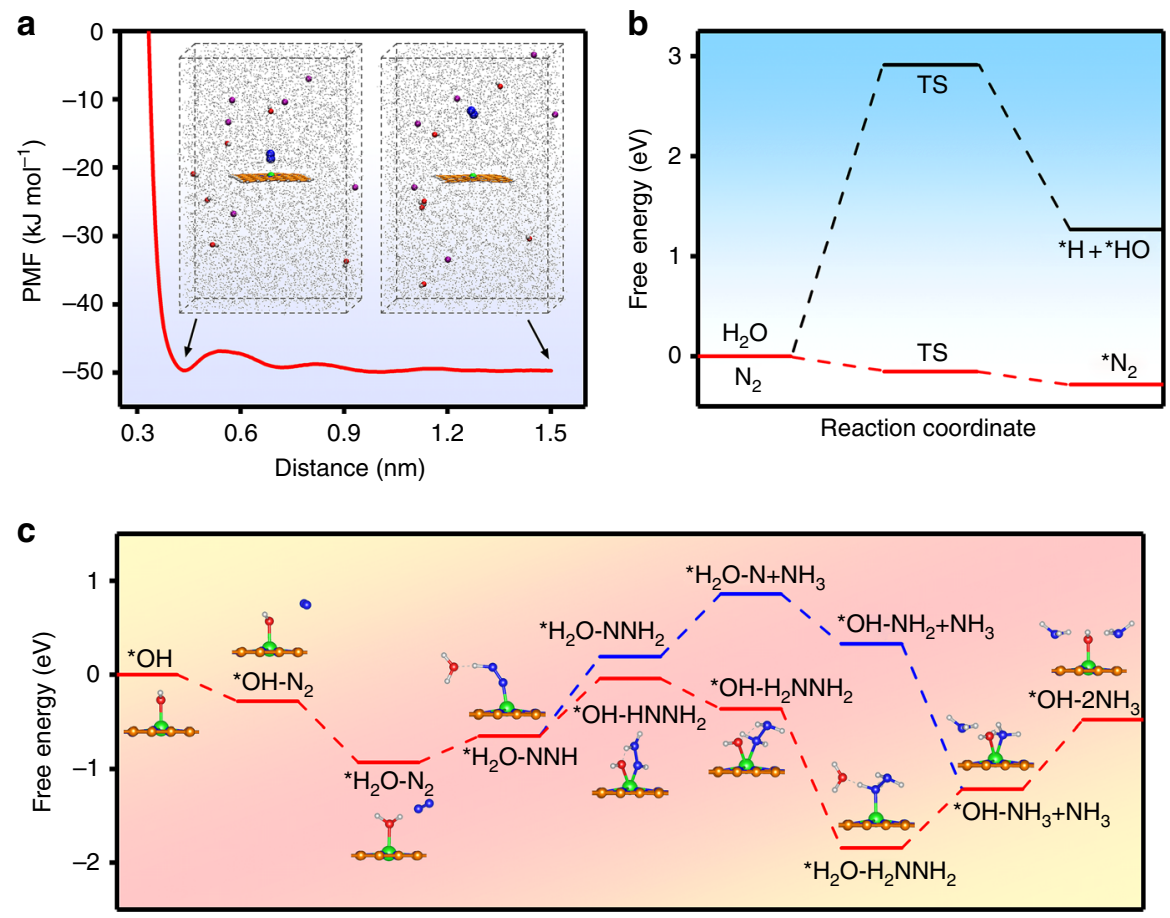

Reaction coordinate

Fig. 4 Computational studies. a Potential of the mean force (PMF) for $\mathrm{N}_{2}$ adsorption on the single-atom dispersed $\mathrm{Fe}-\mathrm{N}-\mathrm{C}\left(\mathrm{Fe}_{\mathrm{SA}}-\mathrm{N}-\mathrm{C}\right)$ in $0.1 \mathrm{M} \mathrm{KOH}$, inset: Molecular dynamics (MD) simulation snapshots at 0.45 and $1.5 \mathrm{~nm}$, with $\mathrm{N}_{2}$, blue spheres; $\mathrm{H}_{2} \mathrm{O}$, gray dots; $\mathrm{OH}^{-}$, red and white sticks; $\mathrm{K}^{+}$, purple spheres. b Calculated energy barriers of the adsorption of hydrogen and nitrogen. $\mathbf{c}$ Free energy diagram for the nitrogen reduction reaction (NRR) on the Fe $\mathrm{SA}_{\mathrm{A}}-\mathrm{N}-\mathrm{C}$ catalyst at $\mathrm{U}=\mathrm{O} \mathrm{V}$. Inset models represent the corresponding adsorbates. The orange, blue, red, green, and gray spheres represent $\mathrm{C}, \mathrm{N}, \mathrm{O}, \mathrm{Fe}$, and $\mathrm{H}$ atoms, respectively

no $\mathrm{NH}_{3}$ was detected, further indicating a reliable $\mathrm{NH}_{3}$ production data. The stability of the catalyst is important for practical use, and it was investigated by consecutive recycling electrolysis at $0 \mathrm{~V}$ vs. RHE. For $\mathrm{Fe}_{\mathrm{SA}}-\mathrm{N}-\mathrm{C}$, no obvious change could be observed in the total current density during 15 consecutive cycles (Supplementary Fig. 14) nor in the ammonia Faradaic efficiency and yield rate (Fig. 3c), suggesting its excellent stability for ambient ammonia synthesis. Careful examination of SEM, TEM, and HAADF-STEM images of $\mathrm{Fe}_{\mathrm{SA}}-\mathrm{N}-\mathrm{C}$ show that the atomically dispersed $\mathrm{Fe}$ atoms were still anchored the $\mathrm{N}$ doped carbon nanosheet without any agglomeration (Supplementary Figs. 15 and 16). The catalyst phase property also shows no obvious change, as confirmed by further characterization with XRD (Supplementary Fig. 17), indicating the robustness of $\mathrm{Fe}_{\mathrm{SA}}-\mathrm{N}-\mathrm{C}$ towards ammonia synthesis.

\section{Discussion}

Emerging cutting-edge operando techniques are considered critical for giving insight into the intrinsic mechanism of catalytic processes compared with ex-situ measurements. In-situ XANES with ultrasensitivity to the electronic properties of the metal was thus conducted under operation conditions to probe if singleatom $\mathrm{Fe}$ was the actual active phase for the NRR (Supplementary Fig. 18). Potentiostatic testing was carried out at $0 \mathrm{~V}$ vs. RHE and the XANES results of the Fe K-edge were collected at different times, as shown in Supplementary Fig. 19. Obviously, once the reaction proceeds, the white-line peak shifted from $7133 \mathrm{eV}$ to a lower energy of $7131 \mathrm{eV}$ after $15 \mathrm{~min}$, suggesting a decreased valence state of $\mathrm{Fe}$. During the NRR process, $\mathrm{N}_{2}$ molecules are fixed to bond with $\mathrm{Fe}$ sites by donating electrons to the unoccupied $d$ orbitals of $\mathrm{Fe}^{22,23}$, thus accounting for the negative shift of its energy position. As the reaction goes on, the adsorption of nitrogen and the desorption of ammonia constantly occur and reach a dynamic balance; thus, the adsorption edge of Fe shows no distinct change from 15 to $30 \mathrm{~min}$. The XANES and EXAFS profiles obtained after the NRR remain almost the same as those obtained before the reaction (Supplementary Fig. 20), which is consistent with the lack of change in the HAADF-STEM images and XRD patterns of the fresh and spent electrocatalysts, again confirming the stability of the single-atom Fe.

Computational studies were performed to understand the unique activity of the NRR on the $\mathrm{Fe}_{\mathrm{SA}}-\mathrm{N}-\mathrm{C}$ catalyst in alkaline medium (Supplementary Fig. 21). The adsorption behavior of $\mathrm{N}_{2}$ towards single-atom $\mathrm{Fe}$ was first explored by $\mathrm{MD}$ simulations. Umbrella sampling was performed to quantify the free energy barrier of $\mathrm{N}_{2}$ access (Supplementary Fig. 22), and the potential of the mean force (PMF) as a function of the distance is shown in Fig. 4a. Clearly, starting from a distance of $1.5 \mathrm{~nm}$, there is only a small energy barrier of $2.38 \mathrm{~kJ} \mathrm{~mol}^{-1}$ at approximately $0.54 \mathrm{~nm}$ for the approaching of $\mathrm{N}_{2}$ molecule. As a result, the $\mathrm{N}_{2}$ molecules tend to accumulate at approximately $0.45 \mathrm{~nm}$ away from the $\mathrm{Fe}$ site, leading to a localized high concentration, which would facilitate the following adsorption and thus benefit the whole NRR process. The competing adsorption between ${ }^{\star} \mathrm{N}_{2}$ and ${ }^{\star} \mathrm{H}$ was then evaluated by DFT calculations in Fig. $4 \mathrm{~b}$. In our case, ${ }^{\star} \mathrm{H}$ comes from water dissociation and the energy barrier of this step is as high as $2.91 \mathrm{eV}$, representing negligible ${ }^{\star} \mathrm{H}$ adsorption. Even if ${ }^{\star} \mathrm{H}$ is adsorbed, its desorption to form $\mathrm{H}_{2}$ is still an endothermic reaction, with a much stronger Gibbs free energy change than those of common transition and noble metals ${ }^{24}$, as shown in Supplementary Fig. 23. Therefore, the HER kinetics are particularly sluggish on the $\mathrm{Fe}_{\mathrm{SA}}-\mathrm{N}-\mathrm{C}$ surface. In contrast, it was found that nitrogen adsorption undergoes a downhill process and the binding Gibbs free energy of ${ }^{\star} \mathrm{N}_{2}$ is as low as $-0.28 \mathrm{eV}$, suggesting a significantly exothermic process. The usual weakness of the low absorbability of nitrogen is thus overcome ${ }^{25}$. 
Notably, considering the experimental environment of $\mathrm{N}_{2^{-}}$ saturated $0.1 \mathrm{M} \mathrm{KOH}$, the solvent effect on NRR cannot be ignored and the adsorption energies of ${ }^{\star} \mathrm{H}_{2} \mathrm{O},{ }^{*} \mathrm{~N}_{2},{ }^{*} \mathrm{OH}^{-}$, and ${ }^{\star} \mathrm{K}^{+}$(Supplementary Fig. 24) are compared in Supplementary Table 3. It turns out that ${ }^{\star} \mathrm{OH}^{-}$is the easiest to adsorb onto $\mathrm{Fe}_{\mathrm{SA}_{\mathrm{A}}}-\mathrm{N}-\mathrm{C}$; thus, the Gibbs free energy for each step of the NRR was calculated based on the $\mathrm{Fe}^{-}{ }^{*} \mathrm{OH}^{-}$structure. The computed energy profiles are depicted in Fig. 4c, and the alternating pathway (Supplementary Fig. 25) is more feasible than the distal pathway (Supplementary Fig. 26), as hydrogenation occurs preferentially between the two $\mathrm{N}$ atoms. The hydrogen tends to first attack the adsorbed ${ }^{\star} \mathrm{OH}^{-}$and the reaction process from ${ }^{\star} \mathrm{OH}^{-}$ to ${ }^{*} \mathrm{H}_{2} \mathrm{O}-\mathrm{N}_{2}$ is completely barrier-less (Fig. $4 \mathrm{c}$ ). This thermodynamically favorable process could contribute to the activation of the following hydrogenation steps. According to the so-called hot atom mechanism, the molecule's vibrational energy level can be enhanced by the energy released in the nitrogen adsorption process ${ }^{26}$. As a result, the reaction barrier of the following nitrogen activation is reduced. The reaction Gibbs free energy of the first hydrogenation step $\left({ }^{\star} \mathrm{H}_{2} \mathrm{O}-\mathrm{N}_{2}+\mathrm{H}^{+}+e^{-} \rightarrow{ }^{*} \mathrm{H}_{2} \mathrm{O}\right.$ $\mathrm{NNH}$ ), which is usually considered the rate-determining step of the whole process, is calculated to be only $0.28 \mathrm{eV}$ uphill after nitrogen adsorption, which is much lower than that of the previously reported noble metal catalyst ${ }^{11}$. The reaction bottleneck is shifted to the last step $\left({ }^{\star} \mathrm{OH}-\mathrm{NH}_{3}+\mathrm{NH}_{3}+\mathrm{H}^{+}+e^{-} \rightarrow{ }^{*} \mathrm{OH}+\right.$ $2 \mathrm{NH}_{3}$ ) and the overall reaction barrier is dramatically reduced. The DFT-calculated free energetics of the HER and NRR rationalize the electrochemical measurements and we can conclude that the desirable performance derives from the preferential nitrogen adsorption and its exothermic effect on the following nitrogen activation.

In summary, we have shown that positively shifting the reaction potential of the NRR enabled a single-atom dispersed Fe-N-C catalyst to achieve a Faradaic efficiency of $56.55 \%$ and a desirable yield rate of $7.48 \mu \mathrm{g} \mathrm{h}^{-1} \mathrm{mg}^{-1}$ under ambient conditions. Comparative experiments indicate both enhanced NRR and suppressed HER performance. The promoted NRR process starts with a very positive onset potential of $0.193 \mathrm{~V}$ vs. RHE and achieves the best performance at $0 \mathrm{~V}$ vs. RHE. To determine reliability of the $\mathrm{NH}_{3}$ production data, an ${ }^{15} \mathrm{~N}$ isotopic labeling experiment using ${ }^{15} \mathrm{~N}_{2}$ as the feeding gas was carried out, and all the produced $\mathrm{NH}_{3}$ were confirmed to come from the electroreduction of $\mathrm{N}_{2}$ catalyzed by $\mathrm{Fe}_{\mathrm{SA}}-\mathrm{N}-\mathrm{C}$. In addition, during consecutive recycling, no obvious change can be observed in the ammonia Faradaic efficiency and yield rate, indicating the excellent stability of the catalyst. The specific mechanism of this excellent activity is unveiled by the MD and DFT calculations. The $\mathrm{Fe}_{\mathrm{SA}}-\mathrm{N}-\mathrm{C}$ structure could effectively attract the access of nitrogen molecules, with a small energy barrier of $2.38 \mathrm{~kJ} \mathrm{~mol}^{-1}$. The obtained localized high concentration of $\mathrm{N}_{2}$ would favor the following adsorption with a particularly low binding Gibbs free energy of $-0.28 \mathrm{eV}$. Moreover, such an exothermic process could provide energy for the following hydrogenation, as suggested by the hot atom hypothesis. As a result, the overall reaction barrier is dramatically reduced, and a highly selective ammonia synthesis is realized.

\section{Methods}

Reagents. Pyrrole $\left(\mathrm{C}_{4} \mathrm{H}_{5} \mathrm{~N}, 98 \%\right)$ was purchased from Sigma-Aldrich. Ferrous chloride tetrahydrate $\left(\mathrm{FeCl}_{2} \cdot 4 \mathrm{H}_{2} \mathrm{O}, \geq 99.0 \%\right)$, hydrogen peroxide solution $\left(\mathrm{H}_{2} \mathrm{O}_{2}, 30\right.$ wt\% in $\mathrm{H}_{2} \mathrm{O}$ ), sodium chloride $(\mathrm{NaCl}, 99.5 \%)$, ammonium persulfate $\left(\left(\mathrm{NH}_{4}\right)_{2} \mathrm{~S}_{2} \mathrm{O}_{8}, \geq 98 \%\right)$, potassium hydroxide $(\mathrm{KOH}, 95 \%)$, phenol $\left(\mathrm{C}_{6} \mathrm{H}_{6} \mathrm{O}, \geq 99.5 \%\right)$, sodium nitroferricyanide dihydrate $\left(\mathrm{C}_{5} \mathrm{FeN}_{6} \mathrm{Na}_{2} \mathrm{O} \cdot 2 \mathrm{H}_{2} \mathrm{O}, 99.0 \%\right)$, sodium citrate dehydrate $\left(\mathrm{C}_{6} \mathrm{H}_{5} \mathrm{Na}_{3} \mathrm{O}_{7} \cdot 2 \mathrm{H}_{2} \mathrm{O}, 99.0 \%\right)$, sodium hydroxide $(\mathrm{NaOH}, 96 \%)$, salicylic acid $\left(\mathrm{C}_{7} \mathrm{H}_{6} \mathrm{O}_{3}, 99.5 \%\right)$, sodium hypochlorite solution ( $\mathrm{NaClO}$, available chlorine $\geq 5.0 \%$ ), ammonium chloride $\left(\mathrm{NH}_{4} \mathrm{Cl}, 99.5 \%\right)$, p-dimethylaminobenzaldehyde $\left(\mathrm{C}_{9} \mathrm{H}_{11} \mathrm{NO}, 99 \%\right)$ were purchased from Aladdin. Hydrochloric acid $(\mathrm{HCl}$,
36.0-38.0\%), sulfuric acid $\left(\mathrm{H}_{2} \mathrm{SO}_{4}, 95.0-98.0 \%\right)$, ethyl alcohol $\left(\mathrm{C}_{2} \mathrm{H}_{5} \mathrm{OH}, 75 \%\right)$, hydrazine monohydrate $\left(\mathrm{N}_{2} \mathrm{H}_{4} \cdot \mathrm{H}_{2} \mathrm{O}, \geq 85.0 \%\right)$ were purchased from Sinopharm Chemical Reagent Co., Ltd. All chemical reagents were used without further purification.

Catalyst preparation. To prepare $\mathrm{Fe}_{\mathrm{SA}}-\mathrm{N}-\mathrm{C}, 2 \mathrm{ml}$ pyrrole was adequately dispersed in deionized water by ultrasonic vibration. Excess ferrous chloride and hydrogen peroxide were added, and the reaction lasted several hours until a bright yellow and transparent solution was obtained. Sodium chloride was further dissolved in the solution to be used as a template. The product was collected by freezedrying to obtain brown powders. The material was then placed in a ceramic boat and carbonized at $600^{\circ} \mathrm{C}$ for $2 \mathrm{~h}$ under argon protection. After removing the salt templates through sufficient washing with a lot of water and ethanol, the products were dried in a vacuum at $60^{\circ} \mathrm{C}$ overnight prior to use. To prepare $\mathrm{N}-\mathrm{C}, 2 \mathrm{ml}$ pyrrole was adequately dispersed in deionized water by ultrasonic vibration. Sodium chloride was dissolved in the solution, followed by the addition of $1 \mathrm{ml} 1 \mathrm{M}$ $\mathrm{HCl}$. Then, $\left(\mathrm{NH}_{4}\right)_{2} \mathrm{~S}_{2} \mathrm{O}_{8}$ solution was dropwise added into the system under vigorous stirring to start the pyrrole polymerization. The solution was freeze-dried after the reaction and was kept in an ice/water bath for $24 \mathrm{~h}$. The obtained material was placed in a ceramic boat and carbonized at $600^{\circ} \mathrm{C}$ for $2 \mathrm{~h}$ under argon protection. After removing the salt templates through sufficient washing with a lot of water and ethanol, the samples were dried in a vacuum at $60^{\circ} \mathrm{C}$ overnight to obtain black powders.

Physical characterization. The morphology was studied via a field emission scanning electron microscope (FESEM, SU8010, Japan) and a field emission transmission electron microscope (FETEM, FEI Tecnai G2 F20 S-TWIN TMP, Hongkong). The dispersion of single Fe atoms was characterized by atomicresolution high-angle annular dark-field scanning transmission electron microscopy on a JEOL JEM-ARM200F instrument equipped with a probe spherical aberration corrector. The iron concentrations of the samples were determined via inductively coupled plasma atomic emission spectroscopy. The EXAFS spectra (Fe K-edge) were collected at 1W1B station in the Beijing Synchrotron Radiation Facility (BSRF). The storage rings of BSRF were operated at $2.5 \mathrm{GeV}$ with a maximum current of $250 \mathrm{~mA}$. Using an Si (111) double-crystal monochromator, data collection was carried out in transmission mode using the ionization chamber for the Fe foil and in fluorescence excitation mode using a Lytle detector for $\mathrm{Fe}_{\mathrm{SA}}-\mathrm{N}-\mathrm{C}$. All spectra were collected in ambient conditions. The composition of the catalysts was characterized by XRD patterns (D8 Advance, Bruker) and Raman spectroscopy (HR evolution, Horiba Jobin Yvon, France).

Cathode preparation. Typically, $1 \mathrm{mg}$ of catalyst and $5 \mu \mathrm{l}$ of Nafion solution (Alfa Aesar, $5 \mathrm{wt} \%$ ) were dispersed in $100 \mu \mathrm{l}$ of ethanol by sonicating for at least $1 \mathrm{~h}$ to form a homogeneous ink. Then, the catalyst ink was loaded onto carbon paper with an area of $1 \times 1 \mathrm{~cm}^{2}$ and dried in $\mathrm{N}_{2}$ atmosphere at $80^{\circ} \mathrm{C}$ for $1 \mathrm{~h}$. The obtained mass loading was $1 \mathrm{mg} \mathrm{cm}^{-2}$

Electrochemical NRR measurements. The reduction of $\mathrm{N}_{2}$ gas was performed in a two-compartment cell at room temperature, which was separated by a Nafion 211 membrane (DuPont). Before the NRR tests, the Nafion membrane was pretreated by successive heating in $\mathrm{H}_{2} \mathrm{O}_{2}(5 \%)$ aqueous solution at $80^{\circ} \mathrm{C}$ for $1 \mathrm{~h}$ and in ultrapure water at $80^{\circ} \mathrm{C}$ for another $1 \mathrm{~h}$. A conventional three-electrode system in an electrochemical workstation was used to conduct electrochemical measurements, with $\mathrm{Fe}_{\mathrm{SA}}-\mathrm{N}-\mathrm{C}$ or $\mathrm{N}-\mathrm{C}$ as the working electrode, Pt foil as the counter electrode, and $\mathrm{Ag} / \mathrm{AgCl}(4 \mathrm{M} \mathrm{KCl})$ as the reference electrode. All potentials were converted to the RHE scale via calibration. Pure $\mathrm{N}_{2}$ was continuously fed into the cathodic compartment, with a properly positioned sparger to ensure that the entire cathode was hit by the $\mathrm{N}_{2}$ gas bubbles during the experiments. The electrochemical NRR was tested in $\mathrm{N}_{2}$-saturated $0.1 \mathrm{M} \mathrm{KOH} \mathrm{(30} \mathrm{ml} \mathrm{in} \mathrm{each} \mathrm{cell} \mathrm{compartment)} \mathrm{at}$ ambient temperature and pressure. The linear sweep voltammetry was scanned at a rate of $50 \mathrm{mV} \mathrm{s}^{-1}$. The potentiostatic tests were tested at different potentials including $0.1,0,-0.1,-0.2,-0.3$, and $-0.4 \mathrm{~V}$ vs. RHE. To avoid the loss of produced $\mathrm{NH}_{3}$ by $\mathrm{N}_{2}$ blowing during the test, another glass tube filled with $0.001 \mathrm{M}$ $\mathrm{H}_{2} \mathrm{SO}_{4}(30 \mathrm{ml})$ as the gas absorption liquid was set at the end of the cell. The total $\mathrm{NH}_{3}$ production yield was the summation of the $\mathrm{NH}_{3}$ in the $0.1 \mathrm{M} \mathrm{KOH}$ and 0.001 $\mathrm{M} \mathrm{H}_{2} \mathrm{SO}_{4}$. After the electrochemical reduction reaction, the electrolyte and gas absorption liquid were both collected and analyzed by chromogenic reactions for qualitative measurements. For comparison, potentiostatic tests in Ar-saturated 0.1 $\mathrm{M} \mathrm{KOH}$ were also conducted in this work.

Determination of the produced ammonia. The concentration of the produced ammonia in the $0.1 \mathrm{M} \mathrm{KOH}$ and $0.001 \mathrm{M} \mathrm{H}_{2} \mathrm{SO}_{4}$ was determined by the indophenol blue method ${ }^{7}$. For the $0.1 \mathrm{M} \mathrm{KOH}$ case, $10 \mathrm{ml}$ of the electrolyte after the NRR potentiostatic test was taken out, and $0.4 \mathrm{ml}$ of the solution containing $5 \mathrm{~g}$ of phenol in $50 \mathrm{ml}$ of ethanol, and $0.4 \mathrm{ml}$ of $0.5 \mathrm{wt} \% \mathrm{C}_{5} \mathrm{FeN}_{6} \mathrm{Na}_{2} \mathrm{O}$ (sodium nitroferricyanide) was successively added. Then, $1 \mathrm{ml}$ of oxidizing solution containing $10 \mathrm{~g}$ of sodium citrate dehydrate, $0.5 \mathrm{~g}$ of sodium hydroxide and $10 \mathrm{ml}$ of sodium hypochlorite in $50 \mathrm{ml}$ of Millipore water was also added into the above solution. For the $0.001 \mathrm{M} \mathrm{H}_{2} \mathrm{SO}_{4}$ case, $2 \mathrm{ml}$ of the electrolyte after the NRR potentiostatic test 
was taken out. Next, $2 \mathrm{ml}$ of a $1 \mathrm{M} \mathrm{NaOH}$ solution containing salicylic acid and sodium citrate dehydrate was added. Then, $1 \mathrm{ml}$ of $0.05 \mathrm{M} \mathrm{NaClO}$ and $0.2 \mathrm{ml}$ of 1 wt $\% \mathrm{C}_{5} \mathrm{FeN}_{6} \mathrm{Na}_{2} \mathrm{O}$ (sodium nitroferricyanide) were also added into the above solution. The UV-Vis absorption spectrum was measured after the mixture was stored in darkness at room temperature for $3 \mathrm{~h}$. The concentration of indophenol blue was measured according to the absorbance at a wavelength of $655 \mathrm{~nm}$. Standard $\mathrm{NH}_{4} \mathrm{Cl}$ solutions at a series of concentrations in $0.1 \mathrm{M} \mathrm{KOH}$ and $0.001 \mathrm{M}$ $\mathrm{H}_{2} \mathrm{SO}_{4}$ were prepared to build the calibration curves and quantify the produced ammonia.

Determination of the produced hydrazine. The concentration of the produced hydrazine in the $0.1 \mathrm{M} \mathrm{KOH}$ and $0.001 \mathrm{M} \mathrm{H}_{2} \mathrm{SO}_{4}$ was determined by the Watt and Chrisp method ${ }^{27}$. In both cases, a mixture of ethanol $(300 \mathrm{ml}), \mathrm{HCl}$ (concentrated, $30 \mathrm{ml})$, and $p$-dimethylaminobenzaldehyde $(5.99 \mathrm{~g})$ was used as a color reagent. For this, $5 \mathrm{ml}$ of the residual electrolyte after the NRR potentiostatic test was taken out, and $5 \mathrm{ml}$ of the above-prepared color reagent was successively added. The resulting solution was stirred for $10 \mathrm{~min}$, and its absorbance was measured at a wavelength of $455 \mathrm{~nm}$. Standard hydrazine monohydrate solutions at a series of concentrations in $0.1 \mathrm{M} \mathrm{KOH}$ and $0.001 \mathrm{M} \mathrm{H}_{2} \mathrm{SO}_{4}$ were prepared to build the calibration curves and quantify the produced hydrazine.

Determination of the HER productions. The $\mathrm{H}_{2}$ was manually sampled and analyzed by gas chromatography (GC, Agilent 7890B).

Calculation of the equilibrium potential. The standard potential for the NRR in alkaline medium was calculated from the standard Gibbs energy of formation at $298.15 \mathrm{~K}$.

$$
\begin{gathered}
\mathrm{N}_{2}(\mathrm{~g})+8 \mathrm{H}_{2} \mathrm{O}+6 \mathrm{e}^{-} \rightarrow 2 \mathrm{NH}_{4} \mathrm{OH}(\mathrm{aq})+6 \mathrm{OH}^{-} \\
\Delta G^{\mathrm{o}}=426.38 \mathrm{kj} \mathrm{mol}^{-1} \\
E^{\circ}=-\Delta G^{\mathrm{o}} / n F \\
=-0.737 \text { V versus Standard Hydrogen Electrode (vs. SHE) }
\end{gathered}
$$

where $n$ is the number of transferred electrons (6) and $F$ is the Faraday constant $\left(96,485 \mathrm{C} \mathrm{mol}^{-1}\right)$

The thermodynamic equilibrium potential under the reaction conditions was calculated according to the Nernst equation, assuming $1 \mathrm{~atm}$ of $\mathrm{N}_{2}$ in the solution.

$$
\begin{aligned}
E=E^{\circ} & -R T / 6 F \times \ln \left[c^{2}\left(\mathrm{NH}_{4} \mathrm{OH}\right) \times c^{6}\left(\mathrm{OH}^{-}\right)\right], \\
& +0.059 \times \mathrm{pH}(\text { vs. } \mathrm{RHE})
\end{aligned}
$$

where $R$ is the gas constant $\left(8.314 \mathrm{~J} \mathrm{~mol}^{-1} \mathrm{~K}^{-1}\right), T$ is the temperature in Kelvin $(298.15 \mathrm{~K}), F$ is the Faraday constant $\left(96,485 \mathrm{C} \mathrm{mol}^{-1}\right), c\left(\mathrm{OH}^{-}\right)$is the hydroxide concentration $(0.1 \mathrm{M})$, and the $\mathrm{pH}$ is 13 . Assuming a $c\left(\mathrm{NH}_{4} \mathrm{OH}\right)$ of $10^{-7} \mathrm{M}$ in the solution, the corresponding thermodynamic equilibrium potentials is determined to be $0.227 \mathrm{~V}$ vs. RHE.

Faradaic efficiency and the yield rate. The Faradaic efficiency (FE) and massnormalized yield rate of $\mathrm{NH}_{3}$ were calculated as below:

$$
\begin{gathered}
\mathrm{FE}\left(\mathrm{NH}_{3}\right)=\left[3 F \times c\left(\mathrm{NH}_{3}\right) \times V\right] / Q, \\
\text { Yield rate } \text { mass }_{3}\left(\mathrm{NH}_{3}\right)=\left[17 c\left(\mathrm{NH}_{3}\right) \times V\right] /(t \times m),
\end{gathered}
$$

where $F$ is the Faraday constant $\left(96,485 \mathrm{C} \mathrm{mol}^{-1}\right), t$ is the electrolysis time $(1 \mathrm{~h})$, $m$ is the loading mass of the catalysts ( $1 \mathrm{mg}), Q$ is the total charge passed through the electrode, $V$ is the volume of the electrolyte, and $c\left(\mathrm{NH}_{3}\right)$ is the measured ammonia concentration.

The electrochemical double-layer capacitance $\left(C_{\mathrm{dl}}\right)$ of the materials was measured to determine their electrochemical surface area (ECSA) using the cyclic voltammograms (CVs) in a small potential range with no faradic processes between 0.9 and $1.0 \mathrm{~V}$ vs. RHE. The plotted current density against scan rate has a liner relationship and its slope is twice the $C_{\mathrm{dl}}$. The ECSA can then be calculated as below:

$$
A_{\mathrm{ECSA}}=C_{\mathrm{dl}} \text { of catalyst }\left(\mathrm{mF} \mathrm{cm}^{-2}\right) / 40 \mu \mathrm{F} \mathrm{cm}^{-2} \text { per } \mathrm{cm}_{\mathrm{ECSA}}{ }^{2}
$$

The surface-area-normalized activity of $\mathrm{NH}_{3}$ was calculated as below:

$$
\text { Yield rate } \text { ECSA }_{3}\left(\mathrm{NH}_{3}\right)=\left[17 c\left(\mathrm{NH}_{3}\right) \times V\right] /\left(t \times A_{\mathrm{ECSA}}\right)
$$

The Faradaic efficiency of $\mathrm{H}_{2}$ was calculated as below:

$$
\mathrm{FE}\left(\mathrm{H}_{2}\right)=2 F v\left(\mathrm{H}_{2}\right) G p_{0} / R T_{0} i_{\text {total }},
$$

where $v\left(\mathrm{H}_{2}\right)$ is the volume concentration of $\mathrm{H}_{2}$ in the exhaust gas from the electrochemical cell (GC data), $G$ is the gas flow rate $\left(\mathrm{ml} \mathrm{min}^{-1}\right.$ at room temperature and ambient pressure), $i_{\text {total }}$ is the steady-state cell current, $p_{0}=1.01 \times$ $10^{5} \mathrm{~Pa}$, and $R=8.314 \mathrm{~J} \mathrm{~mol}^{-1} \mathrm{~K}^{-1}$.

The surface-area-normalized activity of $\mathrm{H}_{2}$ was calculated as below:

$$
\text { Yield rate } \text { ECSA }_{2}\left(\mathrm{H}_{2}\right)=\left[Q \times \mathrm{FE}\left(\mathrm{H}_{2}\right) \times M_{\mathrm{r}}\left(\mathrm{H}_{2}\right)\right] /\left(e \times N_{\mathrm{A}} \times 2\right) \times\left(t \times A_{\mathrm{ECSA}}\right),
$$

where $M_{\mathrm{r}}\left(\mathrm{H}_{2}\right)$ is the relative molecular mass of $\mathrm{H}_{2}, e$ is the electron charge $(1.602 \times$ $\left.10^{-19} \mathrm{C}\right)$, and $N_{\mathrm{A}}$ is the Avogadro constant $\left(6.02 \times 10^{23} \mathrm{~mol}^{-1}\right)$.

${ }^{15} \mathbf{N}$ isotopic labeling experiment. ${ }^{15} \mathrm{~N}_{2}$ (Wuhan Newradar Special Gas Co. Ltd 99 atom $\%{ }^{15} \mathrm{~N}$ ) was used as the feeding gas in the labeling experiment. A low-velocity gas flow system was adopted due to the limited supply and expense of ${ }^{15} \mathrm{~N}_{2}$. After electrolysis at $0 \mathrm{~V}$ vs. RHE for $10 \mathrm{~h}, 10 \mathrm{ml}$ of the electrolyte was taken out, and its $\mathrm{pH}$ was adjusted to 3 by adding $0.5 \mathrm{M} \mathrm{H}_{2} \mathrm{SO}_{4}$. Then, the solution was concentrated to $2 \mathrm{ml}$ and $0.9 \mathrm{ml}$ of the resulting liquid was taken out, followed by adding $0.1 \mathrm{ml}$ of $\mathrm{D}_{2} \mathrm{O}$ as an internal standard. The produced ammonia was quantified using ${ }^{1} \mathrm{H}$ nuclear magnetic resonance measurements ( ${ }^{1} \mathrm{H}$ NMR; Agilent $\left.600 \mathrm{MHz}\right)$.

In-situ XAS characterization for NRR. In-situ and ex-situ XAS data were collected at room temperature at the BL14W1 beamline of Shanghai Synchrotron Radiation Facility (SSRF). Energy calibration was carried out with a Fe foil standard using transmission mode, while the $\mathrm{Si}$ (111) monochromator scanned the incident $\mathrm{X}$-ray photon energy through the Fe K absorption edge. All spectra of the samples were measured in fluorescence mode. The special three-electrode system was assembled using a tailor-made mold with a window for X-ray penetration. The working electrode was prepared by casting $\mathrm{Fe}_{\mathrm{SA}}-\mathrm{N}-\mathrm{C}$ onto carbon paper. A graphite rod was used as the counter electrode, and $\mathrm{Ag} / \mathrm{AgCl}(4 \mathrm{M} \mathrm{KCl})$ was used as the reference electrode. The electrolyte was $\mathrm{N}_{2}$-saturated $0.1 \mathrm{M} \mathrm{KOH}$. Potentiostatic testing at $0 \mathrm{~V}$ vs. RHE was used for in-situ XAS characterization using the CHI660E (Shanghai Chenhua instrument Co., Ltd) electrochemical workstation.

Computational method and model. The umbrella-sampling method was used to calculate the PMF for the adsorption of nitrogen molecules onto $\mathrm{Fe}_{\mathrm{SA}}-\mathrm{N}-\mathrm{C}$. The $\mathrm{Fe}_{\mathrm{SA}}-\mathrm{N}-\mathrm{C}$ was placed at the center of a simulation box $(4 \mathrm{~nm} \times 4 \mathrm{~nm} \times 6 \mathrm{~nm})$ and perpendicular to the $z$-axis, with one $\mathrm{N}_{2}$ molecule right above the center $\mathrm{Fe}$ atom at a distance of $1.5 \mathrm{~nm}$. Then, the box was solvated with $\mathrm{KOH}$ solution (containing 6 $\mathrm{K}^{+}, 6 \mathrm{OH}^{-}$and 3000 water molecules). The entire system was energy-minimized (EM) and NPT-equilibrated (constant number of atoms, pressure, and temperature) at $298 \mathrm{~K}$ and 1 bar for $1 \mathrm{~ns}$

Subsequently, the $\mathrm{N}_{2}$ molecule was pulled towards the Fe atom along the $z$-axis at a rate of $0.01 \mathrm{~nm} \mathrm{ps}^{-1}$ with a force constant of $10^{5} \mathrm{~kJ} \mathrm{~mol}^{-1} \mathrm{~nm}^{-2}$. The trajectory was extracted, and a series of configurations was picked out, with the center of mass position of the $\mathrm{N}_{2}$ molecule in adjacent configurations at $0.03 \mathrm{~nm}$. These consecutive configurations were used as windows for umbrella sampling for $8 \mathrm{~ns}$ at NPT ( $298 \mathrm{~K}, 1$ bar). The temperature and pressure were controlled by the NoseHoover thermostat and Parrinello-Rahman barostat, respectively.

A harmonic force constant of $10^{4} \mathrm{~kJ} \mathrm{~mol}^{-1} \mathrm{~nm}^{-2}$ in all directions was employed to restrain the $\mathrm{Fe}_{\mathrm{SA}}-\mathrm{N}-\mathrm{C}$. For the $\mathrm{N}_{2}$ molecule, a harmonic force constant of $10^{6} \mathrm{~kJ}$ $\mathrm{mol}^{-1} \mathrm{~nm}^{-2}$ was employed during EM and NPT equilibration in all directions but only in the $x-y$ directions during pulling and umbrella sampling. During umbrella sampling, a harmonic force constant of $10^{5} \mathrm{~kJ} \mathrm{~mol}^{-1} \mathrm{~nm}^{-2}$ was employed in the $z$ direction. The weighted histogram analysis method was used to obtain the PMF curve.

The DFT calculations were conducted based on the Cambridge Sequential Total Energy Package (CASTEP). The exchange-correlation function under the generalized gradient approximation (GGA) with norm-conserving pseudopotentials and the Perdew-Burke-Ernzerhof function was adopted to describe the electron-electron interaction. An energy cutoff of $750 \mathrm{eV}$ was used, and a k-point sampling set of $5 \times 5 \times 1$ was tested to be converged. A force tolerance of $0.01 \mathrm{eV}^{-1}$, an energy tolerance of $5.0 \times 10^{-7} \mathrm{eV}$ per atom, and a maximum displacement of $5.0 \times 10^{-4} \AA$ were considered. Each atom in the storage models is allowed to relax to the minimum enthalpy without any constraints. The vacuum space along the $z$-direction is set to be $15 \AA$. The intermediates have been absorbed onto the Fe atom of the substrate.

The complete linear and quadratic synchronous transit method search protocol, the self-consistent field tolerance of $5.0 \times 10^{-7} \mathrm{eV}$, and root mean square convergence of $0.02 \mathrm{eV} / \AA$ were set for transition states.

The adsorption energy $\Delta E$ of the A group on the surface of the substrates was defined as

$$
\Delta E=E_{* \mathrm{~A}}-\left(E_{*}+E_{\mathrm{A}}\right),
$$


where ${ }^{*} \mathrm{~A}$ and ${ }^{*}$ denote the adsorption of the A group onto the substrates and the bare substrates and, $E_{\mathrm{A}}$ denotes the energy of the $\mathrm{A}$ group.

The Gibbs free energy change $(\Delta G)$ of each chemical reaction is calculated by

$$
\Delta G=\Delta E+\Delta \mathrm{ZPE}-T \Delta S+\Delta G_{U}+\Delta G_{\mathrm{pH}},
$$

where $E, \mathrm{ZPE}, T$, and $S$ denote the calculated total energy, zero-point energy, temperature, and entropy, respectively. $\Delta G_{U}=-e U$ ( $U$ is the potential measured against a normal hydrogen electrode) and $\Delta G_{\mathrm{pH}}=-k B T \ln (10) \times \mathrm{pH}$. Here, $T=$ $300 \mathrm{~K}$ and $\mathrm{pH}=13$ are considered.

\section{Data availability}

The data that support the findings of this study are available from the corresponding author upon reasonable request.

Received: 30 August 2018 Accepted: 14 December 2018

Published online: 21 January 2019

\section{References}

1. Gruber, N. \& Galloway, J. N. An Earth-system perspective of the global nitrogen cycle. Nature 451, 293-296 (2008).

2. Pool, J. A., Lobkovsky, E. \& Chirik, P. J. Hydrogenation and cleavage of dinitrogen to ammonia with a zirconium complex. Nature 427, 527-530 (2004).

3. Erisman, J. W., Sutton, M. A., Galloway, J., Klimont, Z. \& Winiwarter, W. How a century of ammonia synthesis changed the world. Nat. Geosci. 1, 636-639 (2008).

4. van der Ham, C. J. M., Koper, M. T. M. \& Hetterscheid, D. G. H. Challenges in reduction of dinitrogen by proton and electron transfer. Chem. Soc. Rev. 43, 5183-5191 (2014).

5. Liu, C., Sakimoto, K. K., Colon, B. C., Silver, P. A. \& Nocera, D. G. Ambient nitrogen reduction cycle using a hybrid inorganic biological inorganicbiological system. Proc. Natl. Acad. Sci. USA 114, 6450-6455 (2017).

6. Shanmugam, K. T. \& Valentine, R. C. Microbial production of ammonium ion from nitrogen. Proc. Natl. Acad. Sci. USA 72, 136-139 (1975).

7. Zhu, D., Zhang, L. H., Ruther, R. E. \& Hamers, R. J. Photo-illuminated diamond as a solid-state source of solvated electrons in water for nitrogen reduction. Nat. Mater. 12, 836-841 (2013).

8. Ali, M. et al. Nanostructured photoelectrochemical solar cell for nitrogen reduction using plasmon-enhanced black silicon. Nat. Commun. 7, 11335 (2016).

9. Pickett, C. J. \& Talarmin, J. Electrosynthesis of ammonia. Nature 317, 652-653 (1985).

10. Kyriakou, V., Garagounis, I., Vasileiou, E., Vourros, A. \& Stoukides, M. Progress in the electrochemical synthesis of ammonia. Catal. Today 286, 2-13 (2017).

11. Bao, D. et al. Electrochemical reduction of $\mathrm{N}_{2}$ under ambient conditions for artificial $\mathrm{N}_{2}$ fixation and renewable energy storage using $\mathrm{N}_{2} / \mathrm{NH}_{3}$ Cycle. $A d v$. Mater. 29, 1604799 (2017).

12. Shi, M. -M. et al. Au sub-nanoclusters on $\mathrm{TiO}_{2}$ toward highly efficient and selective electrocatalyst for $\mathrm{N}_{2}$ conversion to $\mathrm{NH}_{3}$ at ambient conditions. $A d v$. Mater. 29, 1606550 (2017).

13. Singh, A. R. et al. Electrochemical ammonia synthesis-the selectivity challenge. ACS Catal. 7, 706-709 (2017).

14. Kordali, V., Kyriacou, G. \& Lambrou, C. Electrochemical synthesis of ammonia at atmospheric pressure and low temperature in a solid polymer electrolyte cell. Chem. Commun. 0, 1673-1674 (2017).

15. $\mathrm{Li}, \mathrm{S}$. -J. et al. Amorphizing of Au nanoparticles by $\mathrm{CeO}_{\mathrm{x}}-\mathrm{RGO}$ hybrid support towards highly efficient electrocatalyst for $\mathrm{N}_{2}$ reduction under ambient conditions. Adv. Mater. 29, 1700001 (2017).

16. Shi, M. -M. et al. Anchoring PdCu amorphous nanocluster on graphene for electrochemical reduction of $\mathrm{N}_{2}$ to $\mathrm{NH}_{3}$ under ambient conditions in aqueous solution. Adv. Energy Mater. 8, 1800124 (2018).

17. Lv, C. et al. An amorphous noble-metal-free electrocatalyst that enables nitrogen fixation under ambient conditions. Angew. Chem. Int. Ed. 130, 6181-6184 (2017)
18. Chen, $\mathrm{Y}$. et al. Isolated single iron atoms anchored on $\mathrm{N}$-doped porous carbon as an efficient electrocatalyst for the oxygen reduction reaction. Angew. Chem. 129, 7041-7045 (2017).

19. Xiao, M. et al. Microporous framework induced synthesis of single-atom dispersed Fe-N-C acidic ORR catalyst and its in situ reduced $\mathrm{Fe}-\mathrm{N}_{4}$ active site identification revealed by X-ray absorption spectroscopy. ACS Catal. 8, 2824-2832 (2018)

20. Mahmood, N. et al. Electrocatalysts for hydrogen evolution in alkaline electrolytes: mechanisms, challenges, and prospective solutions. Adv. Sci. 5, 1700464 (2018)

21. Wang, J. et al. Ambient ammonia synthesis via palladium-catalyzed electrohydrogenation of dinitrogen at low overpotential. Nat. Commun. 9 , 1795-1801 (2018).

22. Wang, P. et al. Breaking scaling relations to achieve low-temperature ammonia synthesis through $\mathrm{LiH}$-mediated nitrogen transfer and hydrogenation. Nat. Chem. 9, 64-70 (2017).

23. Légaré, M. A. et al. Nitrogen fixation and reduction at boron. Science 359, 896-900 (2018).

24. Nørskov, J. K. et al. Trends in the exchange current for hydrogen evolution. J. Electrochem. Soc. 152, J23-J26 (2005).

25. Suryanto, B. H. R. et al. Rational electrode-electrolyte design for efficient ammonia electrosynthesis under ambient conditions. ACS Energy Lett. 3, 1219-1224 (2018)

26. Gong, $\mathrm{Y}$. et al. Ternary intermetallic $\mathrm{LaCoSi}$ as a catalyst for $\mathrm{N}_{2}$ activation. Nat. Catal. 1, 178-185 (2018).

27. Watt, G. W. \& Chrisp, J. D. Spectrophotometric method for determination of hydrazine. Anal. Chem. 24, 2006-2008 (1952).

\section{Acknowledgements}

We acknowledge the support from the National Natural Science Foundation of China (No. 51622208, No. 21703149, and No. 51872193). We also appreciate Shanghai Synchrotron Radiation Facility (SSRF) and Taiwan Light Source (TLS) for the support of XAS experiments.

\section{Author contributions}

C.Y. and T.Q. conceived and designed this work. M.W. and S.L. prepared materials and performed the material characterization and electrochemical measurement. H.J. conducted the theoretical calculation. J. Zhou, J.L., J.X., and J. Zhong offered help in the material characterization. All authors discussed the results and commented on the manuscript.

\section{Additional information}

Supplementary Information accompanies this paper at https://doi.org/10.1038/s41467018-08120-x.

Competing interests: The authors declare no competing interests.

Reprints and permission information is available online at http://npg.nature.com/ reprintsandpermissions/

Journal peer review information: Nature Communications thanks Hong Jin Fan and the other anonymous reviewer(s) for their contribution to the peer review of this work.

Publisher's note: Springer Nature remains neutral with regard to jurisdictional claims in published maps and institutional affiliations.

Open Access This article is licensed under a Creative Commons Attribution 4.0 International License, which permits use, sharing, adaptation, distribution and reproduction in any medium or format, as long as you give appropriate credit to the original author(s) and the source, provide a link to the Creative Commons license, and indicate if changes were made. The images or other third party material in this article are included in the article's Creative Commons license, unless indicated otherwise in a credit line to the material. If material is not included in the article's Creative Commons license and your intended use is not permitted by statutory regulation or exceeds the permitted use, you will need to obtain permission directly from the copyright holder. To view a copy of this license, visit http://creativecommons.org/ licenses/by/4.0/

(c) The Author(s) 2019 